\title{
Electrospinning Synthesis of
}

Fe304/Eu(DBM)3phen/PVP Multifunctional

Microfibers and Their Structure, Luminescent and

Magnetic properties

\section{Ruifei Qin}

Luoyang Institute of Science and Technology

lina liu ( $\sim$ liuln448@163.com)

Luoyang Institute of Science and Technology https://orcid.org/0000-0002-1298-6941

\section{Research Article}

Keywords: Electrospinning, Multifunctional, Microfibers

Posted Date: March 6th, 2021

DOl: https://doi.org/10.21203/rs.3.rs-270295/v1

License: (c) (i) This work is licensed under a Creative Commons Attribution 4.0 International License.

Read Full License 


\section{Abstract}

Multifunctional $\mathrm{Fe}_{3} \mathrm{O}_{4} / \mathrm{Eu}(\mathrm{DBM})_{3}$ phen/PVP ((DBM: dibenzoylmethane, phen: 1,10-phenanthroline, PVP: polyvinyl pyrrolidone) microfibers were constructed by simple electrospinning process. The structure and morphology of the microfibers were characterized by X-ray diffraction (XRD), scanning electron microscopy (SEM) and transmission electron microscopy (TEM) images. The diameters of pure PVP microfibers and the microfibers doped only with $\mathrm{Fe}_{3} \mathrm{O}_{4}$ nanoparticles (NPs) were uniformly distributed, with an average size of about $360 \mathrm{~nm}$. When $3 \% \mathrm{Eu}(\mathrm{DBM})_{3}$ phen complex and $\mathrm{Fe}_{3} \mathrm{O}_{4} \mathrm{NPs}$ were both added to the precursor for electrospinning, the microfibers became very inhomogeneous in diameter. The photoluminescent properties of pure $\mathrm{Eu}(\mathrm{DBM})_{3}$ phen complex and composite microfibers were also studied. The characteristic emission peaks of $\mathrm{Eu}^{3+}$ appeared in the composite microfibers. The intensities of emission and excitation spectra gradually decrease with adding more $\mathrm{Fe}_{3} \mathrm{O}_{4} \mathrm{NPs}$. The unit mass of the pure europium complex in some composite microfibers gave stronger luminescence than the pure europium complex. The fluorescence lifetime of ${ }^{5} D_{0}$ state in the composite microfibers is longer than that of pure europium complex. Additionally, the magnetic properties of $\mathrm{Fe}_{3} \mathrm{O}_{4} \mathrm{NPs}$ and the composite microfibers were investigated. $\mathrm{Fe}_{3} \mathrm{O}_{4} \mathrm{NPs}$ and composite microfibers were both superparamagnetic. The saturation magnetization of the composite microfibers was smaller than that of pure $\mathrm{Fe}_{3} \mathrm{O}_{4} \mathrm{NPs}$.

\section{Introduction}

Recently, with the increasing demand for integrated devices, single functional materials have been difficult to meet the needs of modern science and technology. Therefore, multifunctional composites including biomedicine, environmental protection, material science, and many other fields have gradually aroused more and more interests among scientists [1-3]. Among such composites, multifunctional luminescent-magnetic composites simultaneously possess excellent magnetism and luminescence, and have been widely used in biomedical applications such as magnetic resonance imaging (MRI), targeted drug delivery, cell labeling and separation [4-6]. Zhuang et al synthesized multifunctional NPs encoded with quantum dots and magnetic NPs for cell tagging and MRI [7]. Li et al synthesized biomimetic immuno-fluorescent magnetic multifunctional nanoprobes for isolation and analysis of tumor cell subpopulations [8]. Fu et al synthesized multifunctional $\mathrm{NaYF}_{4}: \mathrm{Yb}, \mathrm{Er}_{\mathrm{O}} @ \mathrm{PE}_{3} @ \mathrm{Fe}_{3} \mathrm{O}_{4}$ nanocomposites for magnetic-field-assisted upconversion imaging guided photothermal therapy of cancer cells [9].

In recent years, organic dyes, quantum dots and rare earth complexes have been employed as luminescent materials in the luminescent-magnetic composites. However, organic dyes and quantum dots have limited use in large-scale applications due to their short lifetimes, photobleaching and potential toxicity to cells $[10,11]$. Rare earth complexes have some excellent luminescent properties, such as a long fluorescence lifetime, sharply spiked emission spectra, large stokes shift, and high quantum yield [12]. However, pure rare earth complexes usually do not have good thermal stability, mechanical stabilities and machinability, which limits the prospects of these complexes in a wide range of photophysical and other practical applications. To overcome these shortcomings, rare earth complexes were usually incorporated 
into organic, inorganic, or organic-inorganic hybrid matrixes, such as mesoporous materials, sol-gel silica, and polymers [13-15].

Magnetic nanomaterials have attracted increasing interest of scientists owing to their potential applications, such as biomacromolecule separation, drug delivery and release and MRI $[16,17]$. Among the magnetic materials, Superparamagnetic $\mathrm{Fe}_{3} \mathrm{O}_{4}$ has the advantages of high saturation magnetization, non-toxicity and good biocompatibility, and is widely used in the field of biomedicine [18]. Therefore, $\mathrm{Fe}_{3} \mathrm{O}_{4} \mathrm{NPs}$ have been employed as magnetic materials in the luminescent-magnetic composites.

At present, most of luminescent-magnetic nanocomposites are zero-dimensional $\mathrm{Fe}_{3} \mathrm{O}_{4} @$ @rare earth complex core-shell structure $[19,20]$. The fabrication of one-dimensional luminescent-magnetic composites is a new subject [21-23]. Electrospinning is an outstanding technique for treating viscous solutions into continuous fibers or with one-dimensional nanostructures [24, 25].

Based on the above analysis, in this work, $\mathrm{Fe}_{3} \mathrm{O}_{4} / \mathrm{Eu}(\mathrm{DBM})_{3}$ phen/PVP multifunctional microfibers were synthesized via electrospinning process. The synthesis procedure of the multifunctional microfibers is shown in Fig. 1. $\mathrm{Eu}(\mathrm{DBM})_{3}$ phen complex and $\mathrm{Fe}_{3} \mathrm{O}_{4} \mathrm{NPs}$ were first prepared respectively. Then PVP was dissolved into anhydrous ethanol under magnetic stirring for $24 \mathrm{~h}$. $\mathrm{Eu}(\mathrm{DBM})_{3}$ phen complex was introduced to the above solution under magnetic stirring and $\mathrm{Fe}_{3} \mathrm{O}_{4} \mathrm{NPs}$ were introduced to the solution by sonication. PVP microfibers doped with $\mathrm{Fe}_{3} \mathrm{O}_{4} \mathrm{NPs}$ and $\mathrm{Eu}(\mathrm{DBM})_{3}$ phen complex were prepared via electrospinning technique. the structure, photoluminescent and magnetic properties of the multifunctional microfibers were investigated in detail, and some significant results were obtained. This new kind of microfibers combine the advantages of rare earth complexes and $\mathrm{Fe}_{3} \mathrm{O}_{4} \mathrm{NPs}$. They are expected to find applications in biomedical and biochemical fields. In addition, the preparative technique can be extended to fabricate other multifunctional composites.

\section{Experimental Section}

2.1. Materials. Anhydrous ethanol, Ferric chloride hexahydrate $\left(\mathrm{FeCl}_{3} \cdot 6 \mathrm{H}_{2} \mathrm{O}\right)$, Ethylene glycol, Sodium acetate ( $\mathrm{NaAc}$ ), Ethylenediamine were purchased from Sinopharm Chemical Reagent Co., Lid. (Shanghai, China). PVP ( $M w \approx 1300$ 000), 1,10-phenanthroline, dibenzoylmethane, Europium chloride hexahydrate $\left(\mathrm{EuCl}_{3} \cdot 6 \mathrm{H}_{2} \mathrm{O}\right)$ were purchased from Aladdin Chemistry Co., Ltd.

\subsection{Synthesis of $\mathrm{Fe}_{3} \mathrm{O}_{4} / \mathrm{Eu}(\mathrm{DBM})_{3}$ phen/PVP microfibers. $\mathrm{Eu}(\mathrm{DBM})_{3}$ phen complex and $\mathrm{Fe}_{3} \mathrm{O}_{4} \mathrm{NPs}$ was} synthesized according to the traditional method [26-27]. The microfibers were prepared via electrospinning process. $0.5 \mathrm{~g}$ PVP was dissolved in $4.5 \mathrm{~g}$ ethanol at a mass concentration of $10 \%$. The solution was stirred for $24 \mathrm{~h}$ and then $0.015 \mathrm{~g} \mathrm{Eu}(\mathrm{DBM})_{3}$ phen complex was dissolved in that solution under magnetic stirring for $10 \mathrm{~min}$. The mass percentage of $\mathrm{Eu}(\mathrm{DBM})_{3}$ phen complex to PVP is $3 \%$. $\mathrm{A}$ certain amount of $\mathrm{Fe}_{3} \mathrm{O}_{4} \mathrm{NPs}$ were dispersed in the solution under ultrasonic. The mass ratios of $\mathrm{Fe}_{3} \mathrm{O}_{4}$ NPs to PVP for various samples were $0 \%, 10 \%, 20 \%, 30 \%$, respectively. The electrospinning process was 
carried out in air at room temperature, similar to that depicted before [28]. The composite microfibers with $\mathrm{Fe}_{3} \mathrm{O}_{4}$ NPs accounting for $0 \%, 10 \%, 20 \%$ and $30 \%$ of PVP mass were labeled as samples 0F3E, 10F3E, 20F3E and 30F3E, respectively. For comparison, pure PVP microfibers and the composite microfibers containing $20 \% \mathrm{Fe}_{3} \mathrm{O}_{4}$ NPs of PVP were prepared by the same method, and the composite microfibers were labeled as sample 20F0E.

2.5. Characterizations. The data of XRD, the energy-dispersive analysis of $\mathrm{X}$-ray (EDS), The infrared (IR) absorption spectra, FE-SEM and TEM images were measured according to our previous work [29]. The fluorescence dynamics, excitation and emission spectra were recorded using an Edinburgh FLS980 spectrophotometer. The hysteresis loops of the samples were measured on the Physical Property Measurement System (PPMS).

\section{Results And Discussion}

\subsection{Structure and morphology of $\mathrm{Fe}_{3} \mathrm{O}_{4} / \mathrm{Eu}(\mathrm{DBM})_{3}$ Phen/PVP multifunctional microfibers.}

The XRD patterns of different samples are shown in Fig. 2. According to the Powder Diffraction Standard (JCPDS) file on JCPDS 89-0688, all diffraction peaks of $\mathrm{Fe}_{3} \mathrm{O}_{4}$ NPs can easily point to the face-centered cubic phase of $\mathrm{Fe}_{3} \mathrm{O}_{4}$. Except for sample OF3E without $\mathrm{Fe}_{3} \mathrm{O}_{4}$ doping, the diffraction peaks of $\mathrm{Fe}_{3} \mathrm{O}_{4}$ were observed in other composite microfibers with different $\mathrm{Fe}_{3} \mathrm{O}_{4}$ content, which indicated that $\mathrm{Fe}_{3} \mathrm{O}_{4}$ was indeed doped into the microfibers. Furthermore, with the increase of $\mathrm{Fe}_{3} \mathrm{O}_{4}$ doping concentration, the diffraction peaks of $\mathrm{Fe}_{3} \mathrm{O}_{4}$ became stronger and stronger in the composite microfibers. The broad diffraction band at about 20 degree in samples OF3E, 10F3E, 20F3E and 30F3E was attributed to the amorphous PVP.

Figure 3 shows the SEM images of pure PVP fibers, samples 20F0E, OF3E and 20F3E. As shown in Fig. 3a, the diameters of pure PVP microfibers were uniformly distributed, with an average diameter of about $360 \mathrm{~nm}$. The diameters of the microfibers doped only with $\mathrm{Fe}_{3} \mathrm{O}_{4}$ nanoparticles were still uniformly distributed (Fig. 3.3b), and the average diameters were consistent with that of the pure PVP microfibers. However, the surface of the microfibers became less smooth and some humps appeared (inset of Fig. 3b), which were caused by $\mathrm{Fe}_{3} \mathrm{O}_{4} \mathrm{NPs}$ in the microfibers. When $3 \% \mathrm{Eu}(\mathrm{DBM})_{3}$ phen complex and $\mathrm{Fe}_{3} \mathrm{O}_{4} \mathrm{NPs}$ were both added to the precursor for electrospinning, the microfibers became very inhomogeneous in diameter (Fig. 3c-d). The diameters of the microfibers were between $100 \mathrm{~nm}$ and 700 $\mathrm{nm}$. The addition of europium complex may change the conductivity and viscosity of precursor solution and make the size of microfibers ununiform.

In order to further characterize $\mathrm{Fe}_{3} \mathrm{O}_{4} \mathrm{NPs}$ successfully doped into the composite microfibers, TEM images of sample 20F3E were given in Fig. 4. As shown in Fig. 4, $\mathrm{Fe}_{3} \mathrm{O}_{4}$ NPs in the composite microfibers can be clearly seen, indicating that $\mathrm{Fe}_{3} \mathrm{O}_{4}$ NPs were successfully doped into PVP microfibers. Table 1 
shows the energy spectrum test results of sample 20F3E. There are iron and europium elements in the composite microfibers, which also indicates that $\mathrm{Fe}_{3} \mathrm{O}_{4}$ NPs were successfully doped into the microfibers.

Table 1

EDS of sample 20F3E.

\begin{tabular}{|lll|}
\hline Element & Mass percentage (\%) & Atomic percentage (\%) \\
\hline $\mathrm{C}$ & 25.98 & 50.51 \\
\hline $\mathrm{N}$ & 1.97 & 3.28 \\
\hline $\mathrm{O}$ & 19.51 & 28.48 \\
\hline $\mathrm{Fe}$ & 36.53 & 15.27 \\
\hline $\mathrm{Eu}$ & 16.01 & 2.46 \\
\hline
\end{tabular}

FTIR spectra of the different samples are shown in Fig. 5. The FTIR spectra of the composite microfibers were similar to that of pure PVP fibers, indicating that $\mathrm{Eu}(\mathrm{DBM})_{3}$ phen complex in the composite microfibers was encapsulated in the PVP matrix.

\subsection{Excitation and Emission Spectra.}

The excitation and emission spectra of various samples were shown in Fig. 6. The intensity of the emission spectra was weaker than that of the excitation spectra. The emission spectra of all the samples were expanded by a factor of 10 . Compared with the composite microfibers, the excitation and emission spectra of pure europium complex were the strongest. It can be obviously seen that the intensities of emission and excitation spectra gradually decrease with adding more $\mathrm{Fe}_{3} \mathrm{O}_{4} \mathrm{NPs}$. The reason is that both excitation and emission light can be absorbed by the black $\mathrm{Fe}_{3} \mathrm{O}_{4} \mathrm{NPs}$ [22]. With introducing more $\mathrm{Fe}_{3} \mathrm{O}_{4}$ nanoparticles, the light absorption became stronger, which resulted in a decrease in the excitation and emission spectra. Nevertheless, the composite microfibers can also emit bright red light (Fig. 7a), but the luminescence is weaker than that of the pure $\mathrm{Eu}(\mathrm{DBM})_{3}$ phen complex (Fig. 7b).

As shown in Fig. 6, in the pure complex, a wide excitation band ranging from 230 to $510 \mathrm{~nm}$ appears. In the composite microfibers, it is interesting to observe that the excitation band is divided into two parts, with peaks at about 274 and $357 \mathrm{~nm}$, respectively. This suggests that the site symmetry of the composite microfibers is reduced [30]. The excitation peaks of ${ }^{7} \mathrm{~F}_{0^{-}}{ }^{-5} \mathrm{D}_{2}$ and ${ }^{7} \mathrm{~F}_{1}{ }^{-5} \mathrm{D}_{1}$ appear in the excitation spectra of pure $\mathrm{Eu}(\mathrm{DBM})_{3}$ phen complex, but disappear in the excitation spectra of composite fibers. This indicates that in the composite microfibers, the f-f inner shell transitions were quenched by the transfer of nonradiative energy from the highly excited state to some uncertain defect levels, replacing the nonradiative relaxation to ${ }^{5} \mathrm{D}_{0}$ process.

The emission spectra of different samples were tested under the excitation of $365 \mathrm{~nm}$ light. The emission peak positions of the composite microfibers were the same as that of the europium complex. The 
intensities of emission spectra gradually decrease with adding more $\mathrm{Fe}_{3} \mathrm{O}_{4} \mathrm{NPs}$. The characteristic emission peaks of $\mathrm{Eu}(\mathrm{DBM})_{3}$ phen complex were observed, which located at 579,590 and $612 \mathrm{~nm}$. These peaks were attributed to the ${ }^{5} D_{0}-{ }^{7} F_{0}(579 n m),{ }^{5} D_{0}-{ }^{7} F_{1}(590 \mathrm{~nm})$, and ${ }^{5} D_{0}-{ }^{7} F_{2}(612 n m)$ energy level transitions of $\mathrm{Eu}^{3+}$, and the red-light emission at $612 \mathrm{~nm}$ is dominant.

The relative fluorescence intensity $\left({ }^{5} \mathrm{D}_{0}-{ }^{7} \mathrm{~F}_{2}\right)$ in different samples were listed in Table 2 . By comparing the intensity and the concentration of different samples, we can conclude that the unit mass of europium complex in samples 0F3E, 10F3E and 20F3E gave stronger luminescence than the pure europium complex, implying the improvement of outer luminescence efficiency in samples OF3E, 10F3E and 20F3E [31]. Owing to the strong light absorption ability of $\mathrm{Fe}_{3} \mathrm{O}_{4} \mathrm{NPs}$, with adding more $\mathrm{Fe}_{3} \mathrm{O}_{4} \mathrm{NPs}$, the unit mass of the pure europium complex gave weaker and weaker luminescence. The unit mass of europium complex in sample 30F3E gave weaker luminescence than that of pure $\mathrm{Eu}(\mathrm{DBM})_{3}$ phen complex due to the influence of $\mathrm{Fe}_{3} \mathrm{O}_{4} \mathrm{NPs}$ on luminescence. When europium complexes are added to PVP matrix, PVP inhibits the vibrational transition. As a consequence, more energy was transferred to $\mathrm{Eu}^{3+}$, leading to the improvement of photoluminescence.

Table 2

The content of Eu complex, relative emission intensity and exponential lifetime of samples 30F3E, 20F3E, 10F3E, OF3E and pure Eu complex.

\begin{tabular}{|lccccc|}
\hline Sample & $\mathrm{Eu}(\mathrm{DBM})_{3}$ phen & OF3E & 10F3E & 20F3E & 30F3E \\
\hline Content of $\mathrm{Eu}(\mathrm{DBM})_{3}$ phen (mass \%) & 100 & 3 & 2.73 & 2.5 & 2.31 \\
\hline relative intensities of ${ }^{5} \mathrm{D}_{0^{-}}{ }^{7} \mathrm{~F}_{2}$ & 1 & 18.4 & 7.89 & 2.30 & 0.58 \\
\hline Exponential lifetime $(\mu \mathrm{s})$ & 396 & 596 & 582 & 561 & 604 \\
\hline
\end{tabular}

\subsection{Fluorescence Dynamics.}

Figure 8 shows the fluorescence decay curves of ${ }^{5} \mathrm{D}_{0}{ }^{-7} \mathrm{~F}_{2}$ emissions under $365 \mathrm{~nm}$ excitation at room temperature. The results show that the emissions of ${ }^{5} \mathrm{D}_{0}-{ }^{7} \mathrm{~F}_{2}$ decay exponentially in all the samples. As shown in Table 2, the exponential lifetimes are 396, 596, 582, 561 and $604 \mu \mathrm{s}$ in the pure complexes, and in samples, OF3E, 10F3E, 20F3E, 30F3E, respectively. The results show that the fluorescence lifetime of ${ }^{5} D_{0}$ state in composite fiber is obviously longer than that of pure $\mathrm{Eu}(\mathrm{DBM})_{3}$ phen complex. In the composite microfibers, the surrounding environment of $\mathrm{Eu}^{3+}$ has changed, which may affect the radiation transition rate of $\mathrm{Eu}^{3+}[32]$, inducing the change of the fluorescence life of ${ }^{5} \mathrm{D}_{0}$ level in the composite microfibers.

\subsection{Magnetic properties.}

Hysteresis loops of $\mathrm{Fe}_{3} \mathrm{O}_{4} \mathrm{NPs}$, samples 20F0E and 20F3E are shown in Fig. 9. The Y-axis values of the samples 20F0E and 20F3E were expanded by a factor of four. $\mathrm{Fe}_{3} \mathrm{O}_{4} \mathrm{NPs}$ and composite microfibers are 
both superparamagnetic. No remanence was observed when the applied magnetic field was removed. The superparamagnetic properties make it possible for them to be used in targeted drug transportation [33]. According to the previous literature reports [34], $\mathrm{Fe}_{3} \mathrm{O}_{4} \mathrm{NPs}$ with the size of less than 20-30 nm exhibited superparamagnetic properties, and $\mathrm{Fe}_{3} \mathrm{O}_{4} \mathrm{NPs}$ with the size of larger than $30 \mathrm{~nm}$ exhibited ferromagnetic properties. In our work, the size of $\mathrm{Fe}_{3} \mathrm{O}_{4}$ nanoparticles is larger than $30 \mathrm{~nm}$, but it exhibited superparamagnetic properties. This is due to the existence of magnetite NPs smaller than $30 \mathrm{~nm}$ in the larger $\mathrm{Fe}_{3} \mathrm{O}_{4} \mathrm{NPs}$. The saturation magnetization of $\mathrm{Fe}_{3} \mathrm{O}_{4} \mathrm{NPs}$, samples 20F0E and 20F3E was 80.2, 7.0 and $2.1 \mathrm{emu} / \mathrm{g}$, respectively. Due to the reduced proportion of $\mathrm{Fe}_{3} \mathrm{O}_{4}$ in the composite microfibers, the saturation magnetization of the composite microfibers was smaller than that of pure $\mathrm{Fe}_{3} \mathrm{O}_{4} \mathrm{NPs}$.

Compared with sample 20F0E, the saturation magnetization of sample 20F3E also decreased, indicating that europium complex may have some effect on the magnetism of the $\mathrm{Fe}_{3} \mathrm{O}_{4} \mathrm{NPs}$.

\section{Conclusions}

In summary, multifunctional $\mathrm{Fe}_{3} \mathrm{O}_{4} / \mathrm{Eu}(\mathrm{DBM})_{3}$ phen/PVP microfibers were synthesized by electrospinning technique. XRD, SEM, TEM and EDS results indicated that $\mathrm{Fe}_{3} \mathrm{O}_{4}$ NPs were successfully doped into the composite microfibers. The photoluminescent properties of pure $\mathrm{Eu}(\mathrm{DBM})_{3}$ phen complex and composite microfibers were also studied. The characteristic emission peaks of $\mathrm{Eu}(\mathrm{DBM})_{3}$ phen complex were observed, which located at 579, 590 and $612 \mathrm{~nm}$, and the red-light emission at $612 \mathrm{~nm}$ is dominant. The luminescence of the composite microfibers is weaker than that of the pure europium complex. With adding more $\mathrm{Fe}_{3} \mathrm{O}_{4} \mathrm{NPs}$, the unit mass of the pure $\mathrm{Eu}(\mathrm{DBM})_{3}$ phen complex gave weaker luminescence. The fluorescence lifetime of the composite fibers is longer than that of pure $\mathrm{Eu}(\mathrm{DBM})_{3}$ phen complex. $\mathrm{Fe}_{3} \mathrm{O}_{4} \mathrm{NPs}$ and composite microfibers were both superparamagnetic. This new kind of microfibers possess both magnetism and luminescence, which makes it a material with great potential for application in targeted drug delivery, biomedicine and biochemistry and so on.

\section{Declarations}

Acknowledgements. The authors acknowledge the financial support from the National Natural Science Foundations of China (No. 51802139, 11905096 and 51801092), and the Natural Science Foundations of Henan province (No. 18B140007, 20B140009, 19A430020 and 21A140016).

\section{Interest statement}

We declare that we have no financial and personal relationships with other people or organizations that can inappropriately influence our work, there is no professional or other personal interest of any nature or kind in any product, service and/or company that could be construed as influencing the position presented in, or the review of, the manuscript entitled.

\section{References}


[1] X. Yao, X. Niu, K.X Ma, P. Huang, J. Grothe, S. Kaskel, Y. Zhu, Small, 13 (2017) 1602225 (1-11).

[2] F. Yang, A. Skripka, M.S. Tabatabaei, S.H Hong, F. Ren, Y. Huang, J.K. Oh, S. Martel, X. Liu, F. Vetrone, D Ma, Chem. Mater. 31 (2019) 3201-3210.

[3] Z. Naghshbandi, N. Arsalani, M.S. Zakerhamidi, K.E. Geckeler, Appl. Surf. Sci. 443 (2018) 484-491.

[4] Y. Fang, C. Xing, S. Zhan, M. Zhao, M. Li, H. Liu, C. Wang, ACS Biomater. Sci. Eng. 5 (2019) 6779-6793.

[5] F. Arteaga-Cardona, J.O. Estévez, M.A. Méndez-Rojas, S. Hidalgo-Tobón, P. Dies-Suarez, N.R. SilvaGonzález, J.M.G. Jiménez, G.N. Cherr, U. Salazar-Kuri, Dalton Trans. 49 (2020) 4376-4389.

[6] S. Li, X. Shi, H. Wang, L. Xiao, J. Biomed Mater Res. 108 (2020) 1-12.

[7] Q. Zhuang, X. Wang, Z. Geng, H. Peng, Nanotechnology. 31 (2020) 065101 (1-7).

[8] Q. Li, Z. Liao, L. Han, L. Li, Y. Song, E. Song, Adv. Funct. Mater. 30 (2020) 2004963 (1-11).

[9] S. Fu, Y. Ding, T. Cong, X. Yang, X. Hong, B. Yu, Y. Li, Y. Liu, Dalton Trans. 48 (2019) 12850-12857.

[10] Q. Ma, Y. Nakane, Y. Mori, M. Hasegawa, Y. Yoshioka, T.M. Watanabe, K. Gonda, N. Ohuchi, T. Jin, Biomaterials 33 (2012) 8486-8494.

[11] J.C. Park, M.K. Yu, G. An, S. Park, J. Oh, H.J. Kim, J. Kim, E.K. Wang, H. Hong, Y.S. Ha, T.H. Choi, K. Jeong, Y. Chang, M.J. Welch, S. Jon, J. Yoo, Small, 24 (2010) 2863-2868.

[12] S.S. Syamchand, G. Sony, J Lumin, 165 (2015) 190-215.

[13] H. Zhang, H. Song, B. Dong, L. Han, G. Pan, X. Bai, L. Fan, S. Lu, H. Zhao, F. Wang, J. Phys. Chem. C 112 (2008) 9155-9162.

[14] Q. Zuo, B. Li, L. Zhang, Y. Wang, Y. Liu, J. Zhang, Y. Chen, L. Guo, J Solid State Chem. 183 (2010) 1715-1720.

[15] P. Yang, Z. Quan, Z. Hou, C. Li, X. Kang, Z. Cheng, J. Lin, Biomaterials, 30 (2009) 4786-4795.

[16] M. Pooresmaeil, H. Namazi, J. Alloys Compd, 846 (2020) 156419 (1-12).

[17] N. Akram, W. Ma, J. Guo, Y. Guo, Z. Yansong, A. Hassan, J. Wang, Chem. Phys. 540 (2021) 110974 (111).

[18] L.L. Zhang, S. Tong, Q.B. Zhang, G. Bao, ACS Appl. Nano Mater. 3 (2020) 6785-6797.

[19] H.X. Peng, G.X. Liu, X.T. Dong, J.X. Wang, J. Xu, W.S. Yu, J. Alloys compd. 509 (2011) 6930-6974.

[20] Z.W. Sun, L.Z. Tong, D.M. Liu, J.H. Shi, H. Yang, J. Mater. Chem. 22 (2012) 6280-6284. 
[21] X. Li, Q. Ma, J. Tian, X. Xi, D. Li, X. Dong, W. Yu, X. Wang, J. Wang, G. Liu, Nanoscale, 9 (2017) 1891818930.

[22] J. Tian, Q. Ma, W. Yu, D. Li, X. Dong, G. Liu, J. Wang, Mater. Design. 170 (2019) 107701 (1-11).

[23] Y. Xie, Q. Ma, H. Qi, Y. Song, J. Tian, W. Yu, X. Dong, D. Li, G. Liu, J. Wang, J. Mater. Chem. C, 7 (2019) 9075-9086.

[24] F. Zhan, X. Yan, J. Li, F. Sheng, B, Li, Food Chem. 337 (2021) 127763 (1-9).

[25] N. Yoshiyasu, K. Mikiya, S. Shin-ichiiro, RSC Adv. 10 (2020) 38045-38054.

[26] H. Bauer, J. Blanc, D.L. Ross, J. Am. Chem. Soc.86 (1964): 5125-5131.

[27] Y.H. Zhang, Z.S Su, B. Li, L.M. Zhang, D. Fan, H.P. Ma, ACS Appl. Mater. Interfaces 8 (2016) 1234412351.

[28] L. Liu, B. Li, J. Zhang, R. Qin, H. Zhao, X. Ren, Mater. Res. Bull. 44 (2009) 2081-2086.

[29] L. Liu, B. Li, R. Qin, H. Zhao, X. Ren, Z. Su, Nanotechnology, 21 (2010) 285701 (1-8).

[30] H. Zhang, H. Song, H. Yu, X. Bai, S. Li, G. Pan, Q. Dai, T. Wang, W. Li, S. Lu, X. Ren, H. Zhao, J. Phys. Chem. C 111 (2007) 6524-6527.

[31] S. Li, H. Song, W. Li, X. Ren, S. Lu, G. Pan, L. Fan, H. Yu, H. Zhang, R. Qin, Q. Dai, T. Wang, J. Phys. Chem. B 110 (2006) 23164-23169.

[32] H. Zhang, H. Song, H. Yu, S. Li, X. Bai, G. Pan, Q. Dai, T. Wang, W. Li, S. Lu, X. Ren, H. Zhao, X. Kong, Appl. Phys. Lett. 90 (2007) 103103 (1-3).

[33] X. Sun, B. Dong, H. Xu, S. Xu, X. Zhang, Y. Lin, L. Xu, X. Bai, S. Zhang, H. Song, ACS Appl. Mater. Interfaces. 9(2017) 11451-11460.

[34] X. Xu, C. Deng, M. Gao, W. Yu, P. Yang, X. Zhang, Adv. Mater. 18(2006) 3289-3293.

\section{Figures}




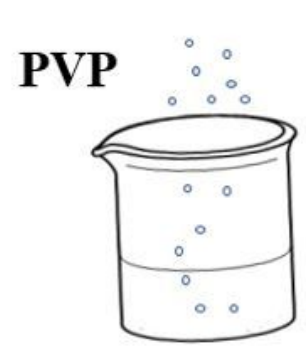

Ethanol

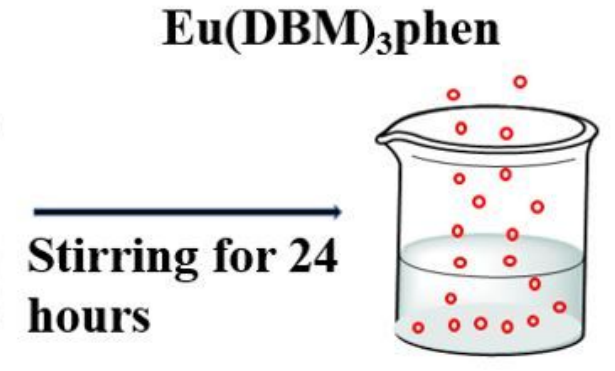

Ethanol solution of PVP

Composite nanofibers

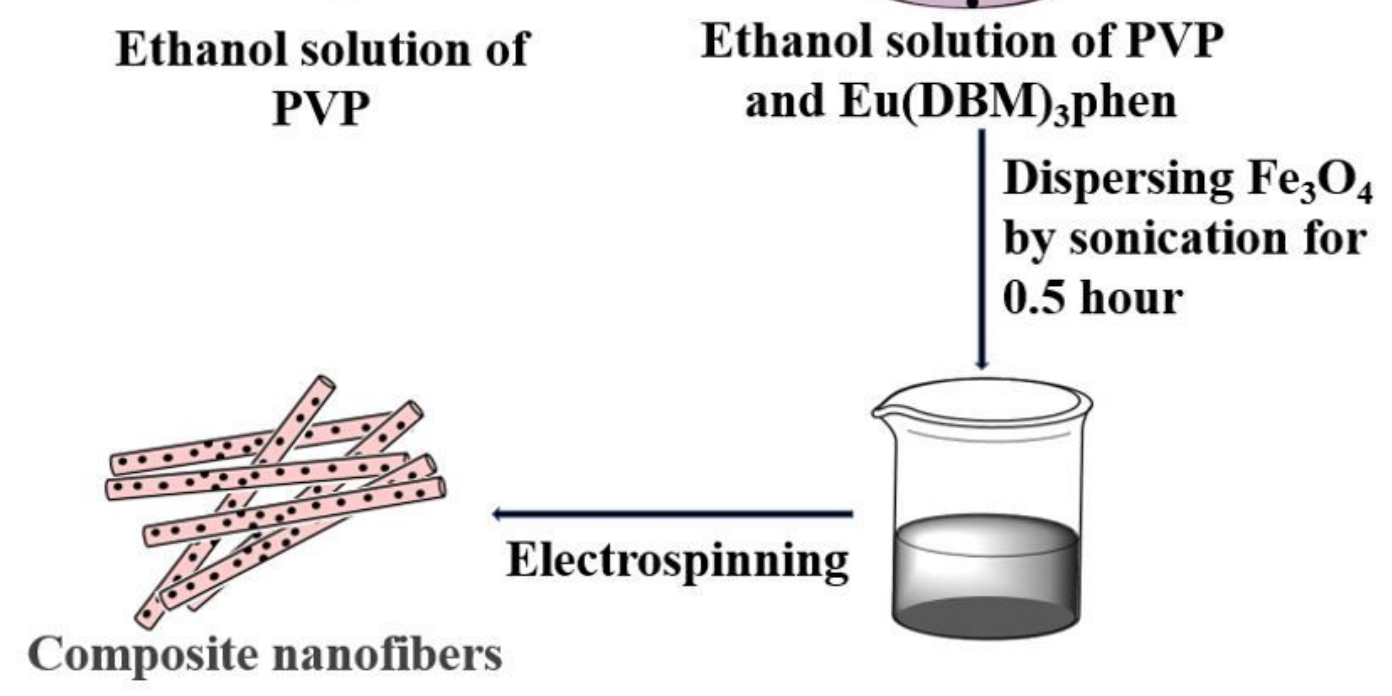

Figure 1

Schematic diagram of the synthetic procedure. 


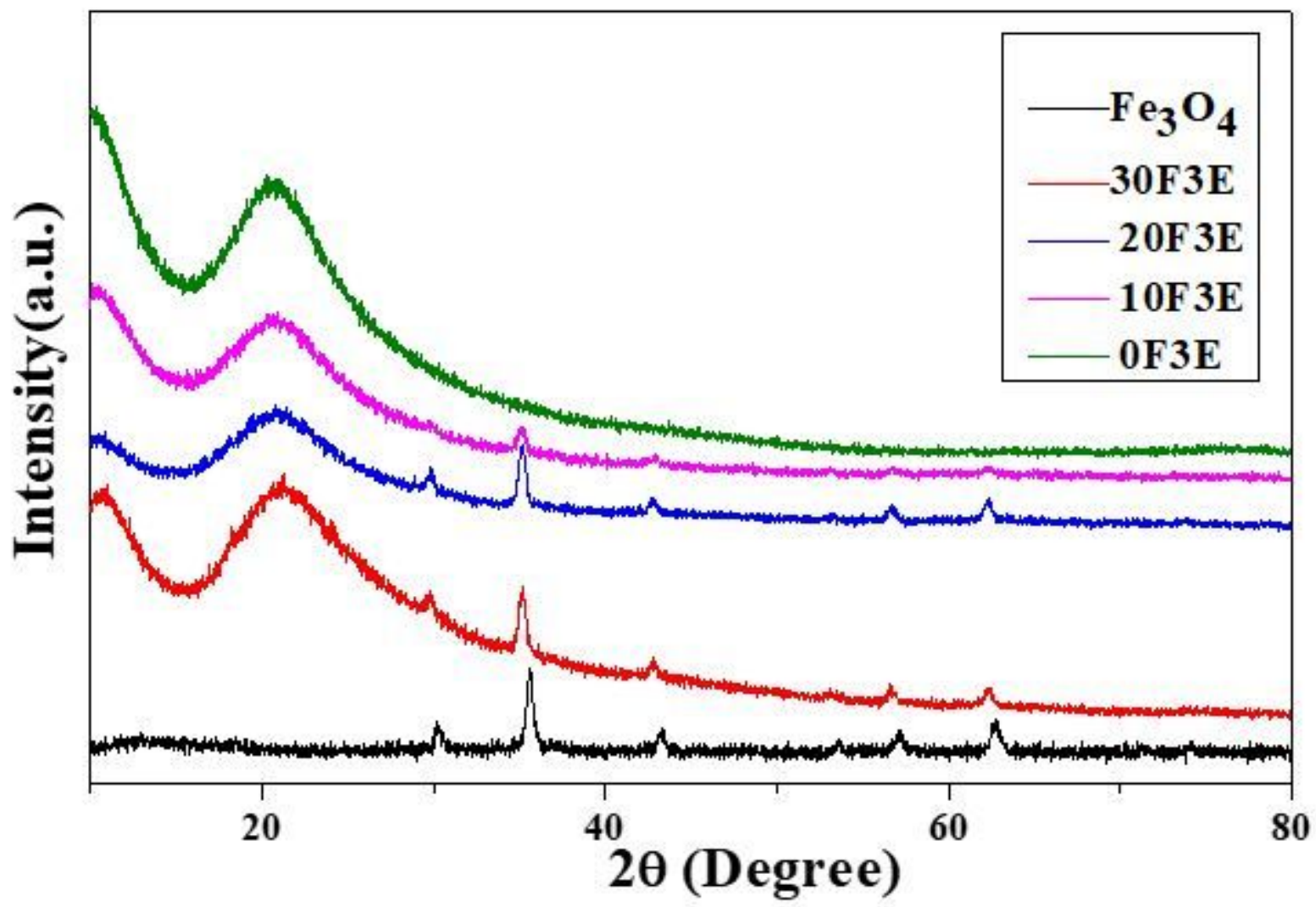

Figure 2

XRD patterns of pure Fe304 NPs, samples 30F3E, 20F3E, 10F3E and 0F3E. 


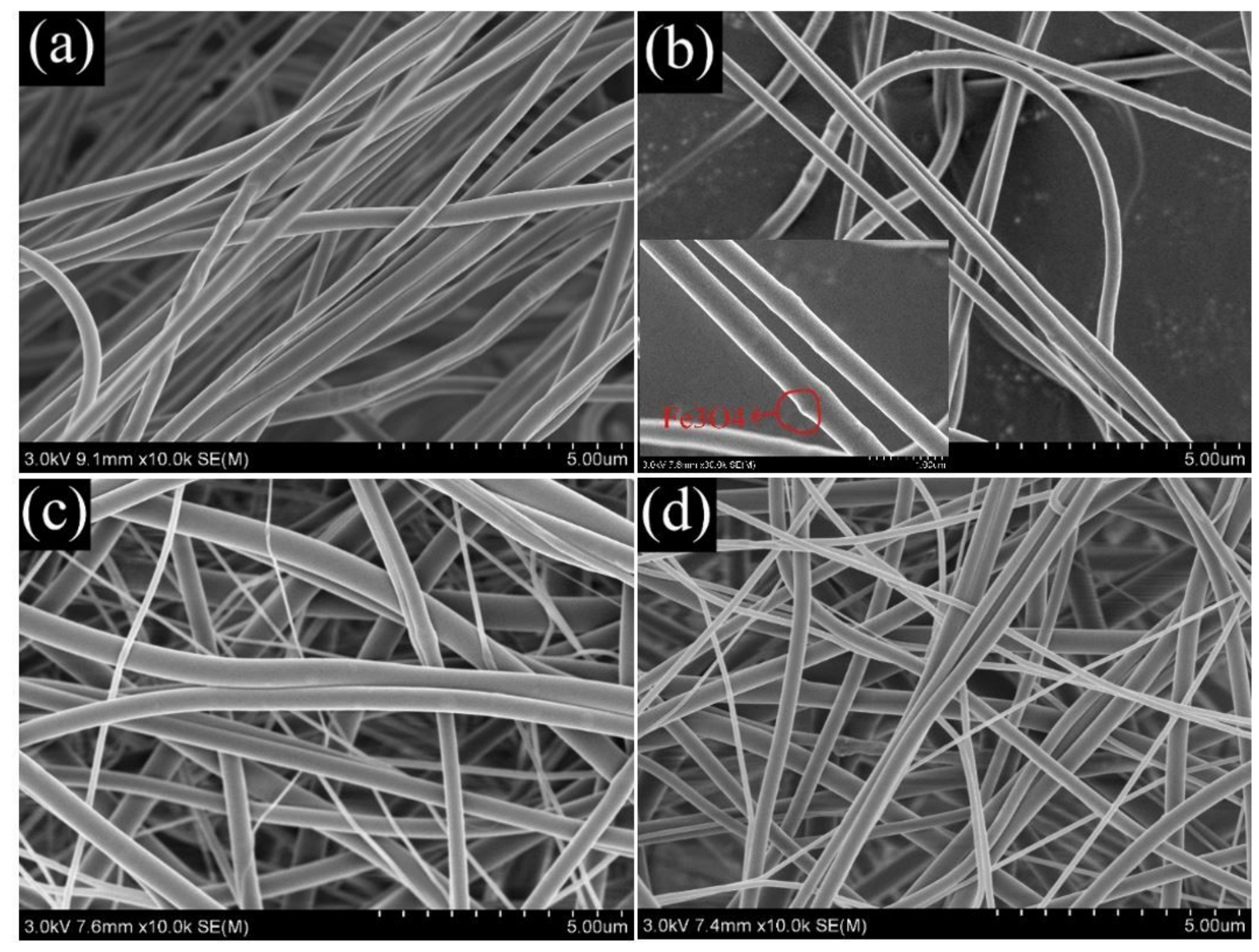

Figure 3

SEM images of (a) pure PVP fibers; (b) sample 20F0E; inset: magnified view of sample 20F0E; (c) sample OF3E; (d) sample 20F3E. 

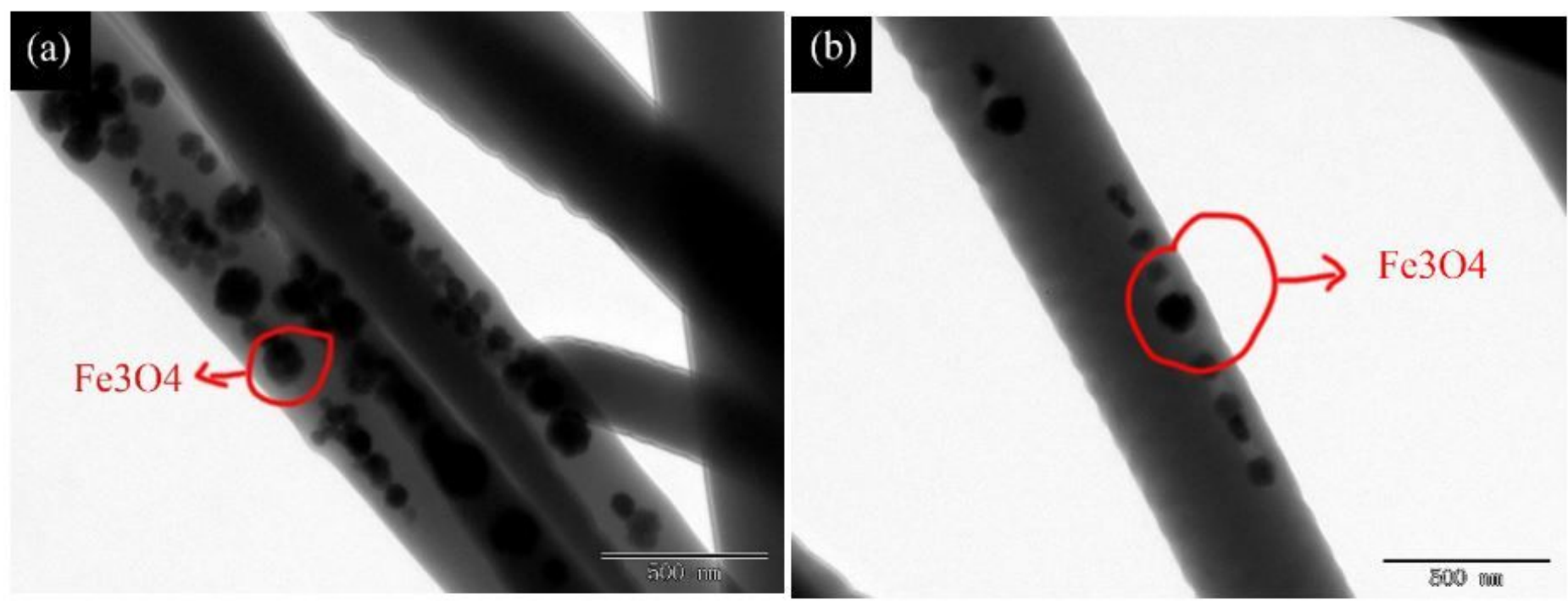

Figure 4

TEM images of sample 20F3E.

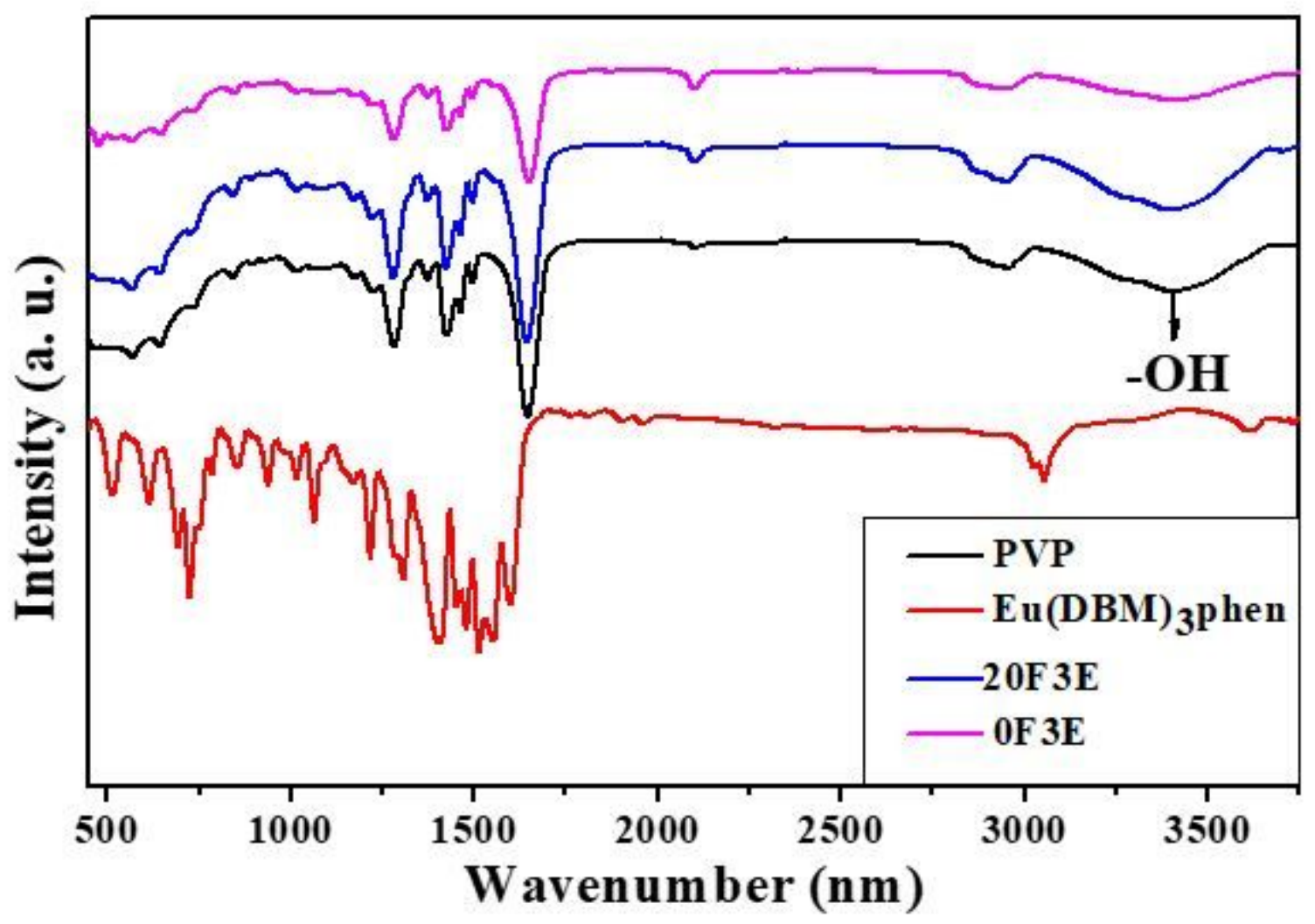

Figure 5

FTIR spectra of pure PVP fibers, pure Eu complex; samples 20F3E and OF3E. 


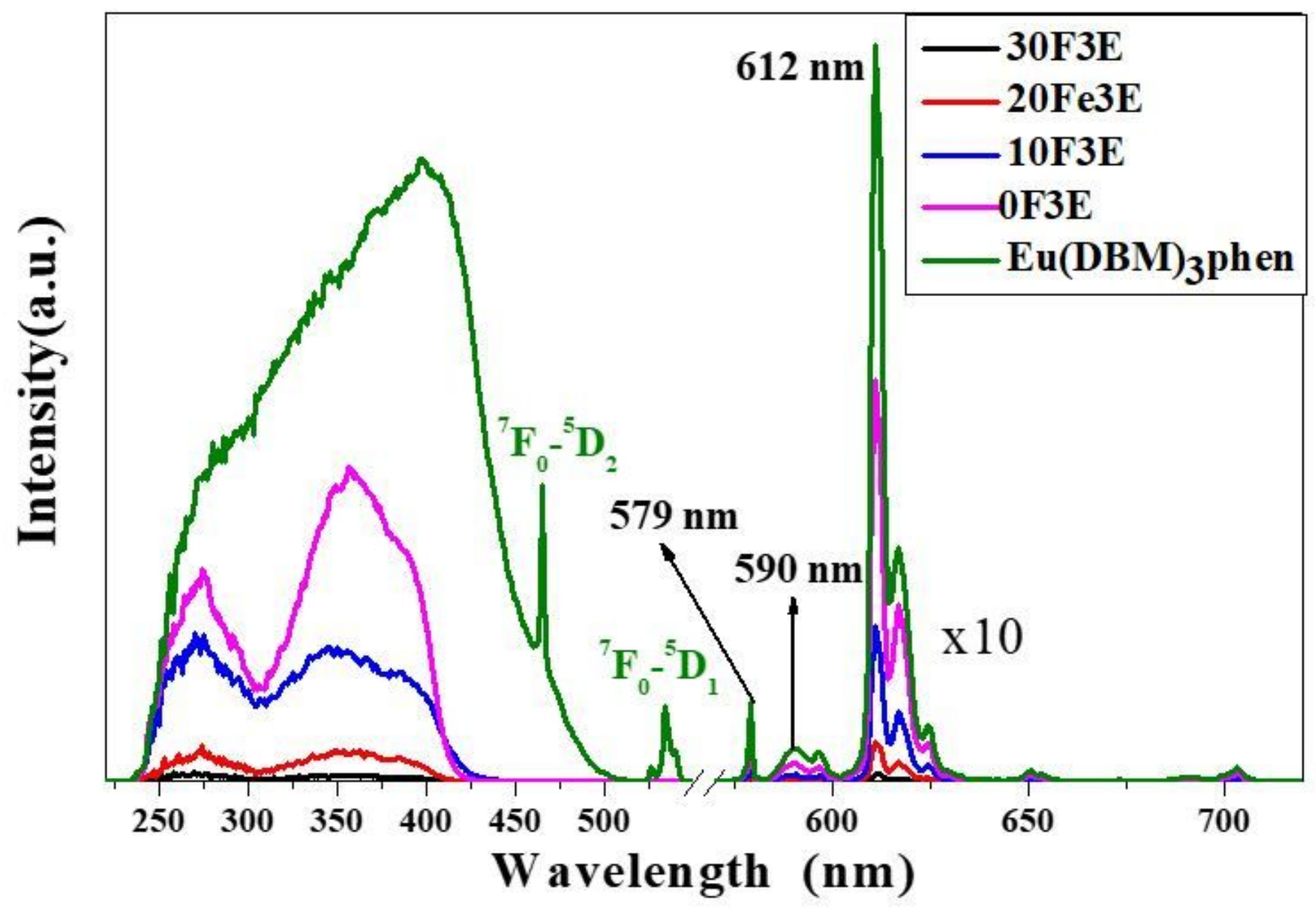

Figure 6

Excitation spectra $(\lambda e m=612 \mathrm{~nm})$ and emission spectra $(\lambda e x=365 \mathrm{~nm})$ of samples $30 \mathrm{FOE}, 20 \mathrm{~F} 0 \mathrm{E}, 10 \mathrm{~F} 0 \mathrm{E}$, OF3E and pure Eu complex. 


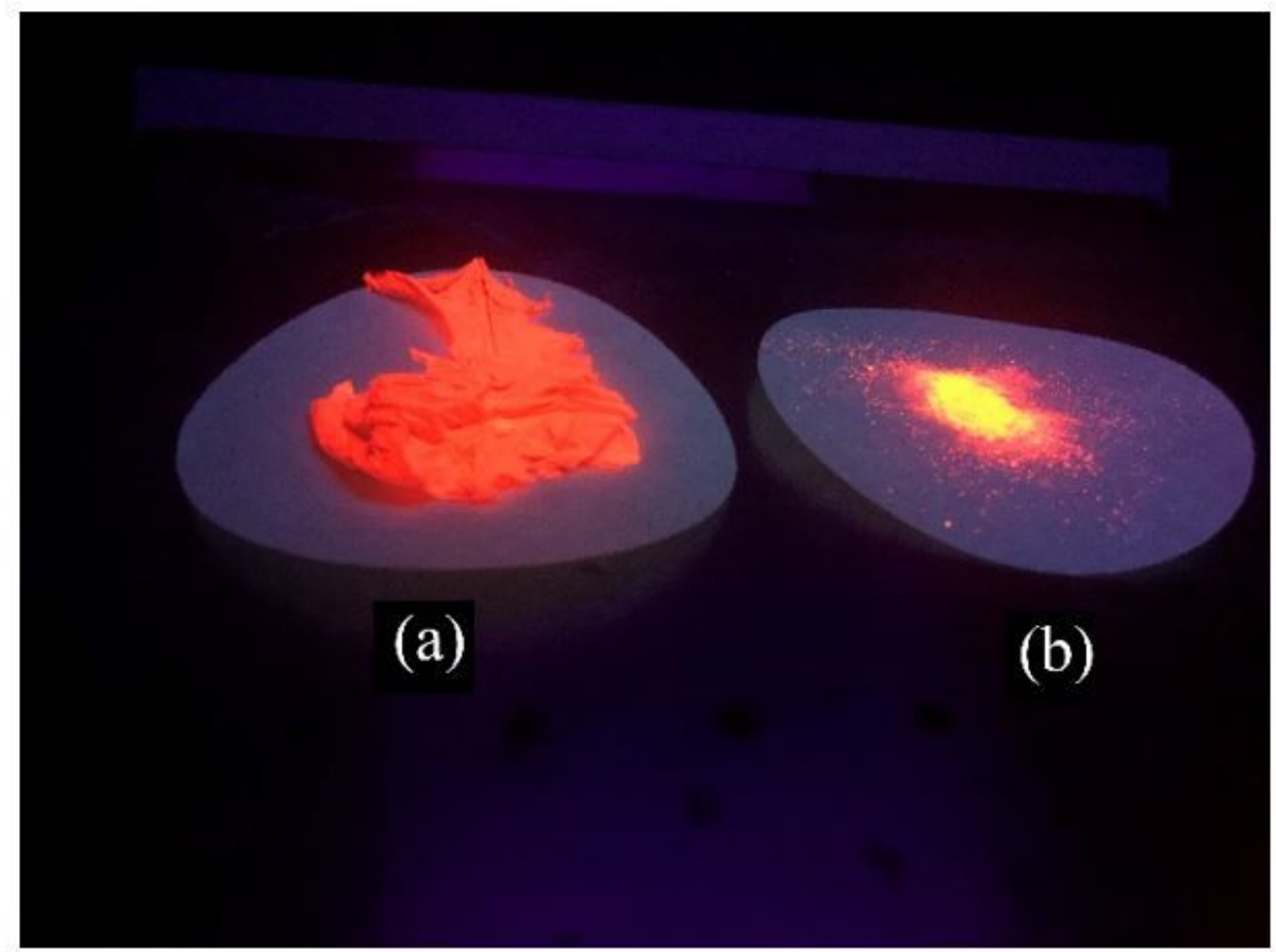

Figure 7

Photographs of (a) sample 20F3E and (b) pure Eu complex under $365 \mathrm{~nm}$ Hg lamp. 


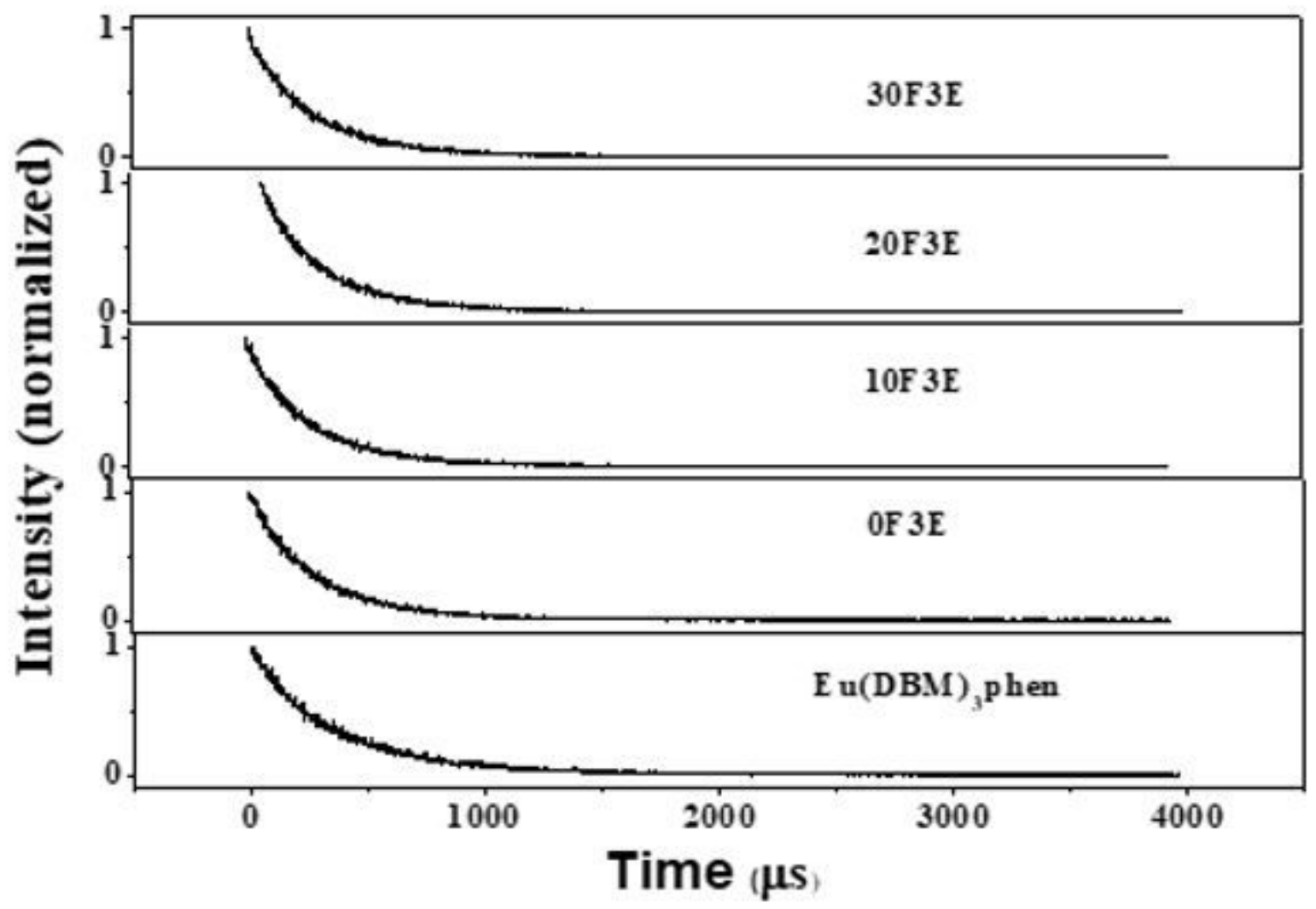

Figure 8

Fluorescence decay dynamics of the 5D0-7F2 transitions ( $\lambda$ ex $=365 \mathrm{~nm}$ ) in samples 30F0E, 20F0E, 10F0E, OF3E and pure Eu complex (room temperature). 


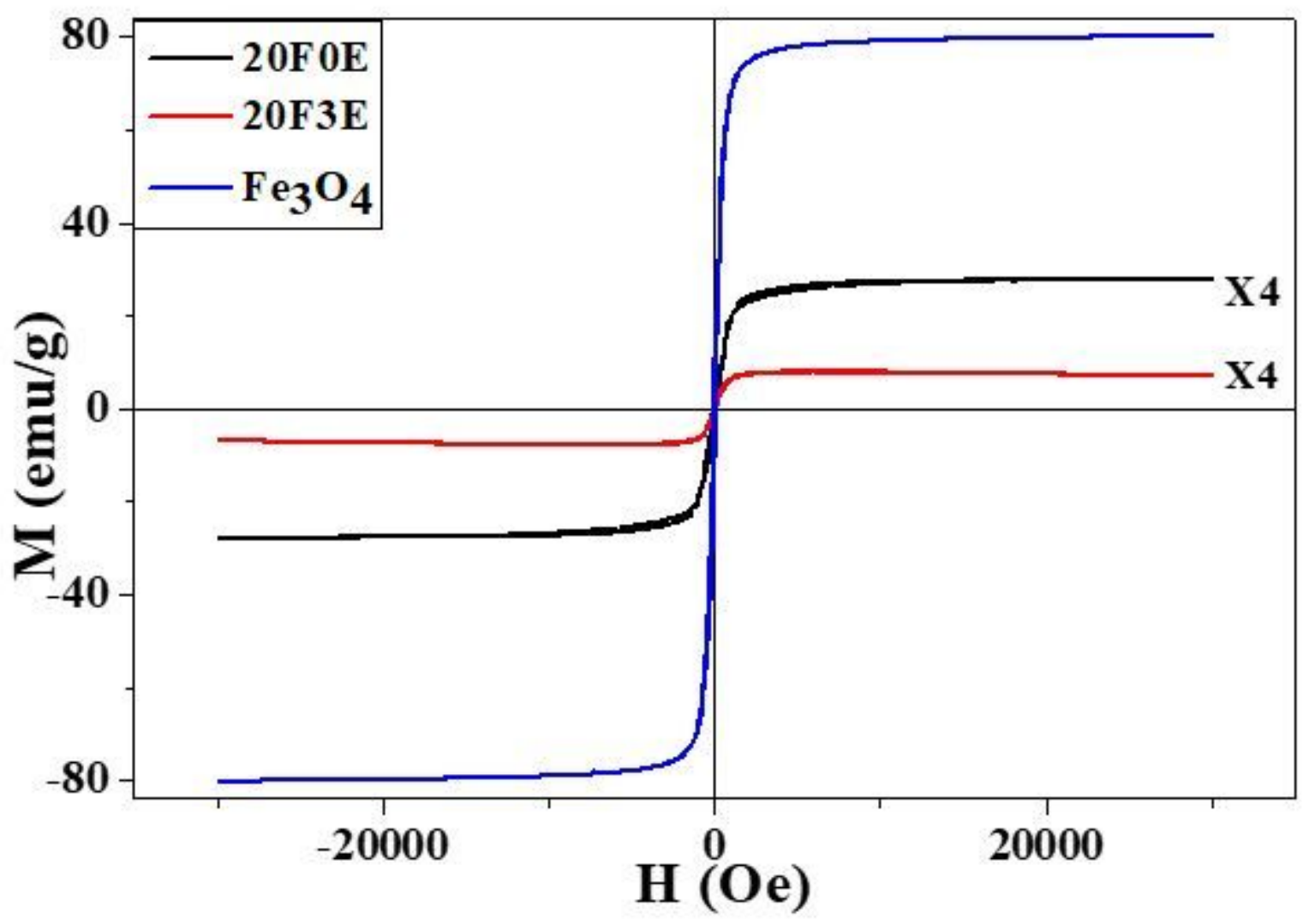

Figure 9

The magnetic hysteresis loops of samples 20F0E, 20F3E and pure Fe304 nanoparticles. 